\title{
Canadian credentialing guidelines for endoscopic retrograde cholangiopancreatography
}

\author{
Jonathon Springer MD FRCPC ${ }^{1}$, Robert Enns MD FRCPC ${ }^{2}$, \\ Joseph Romagnuolo MD FRCPC FASGE MScEpid ${ }^{3}$, Terry Ponich MD FRCPC ${ }^{4}$, \\ Alan N Barkun MD CM MSC FRCPC ${ }^{5}$, David Armstrong MA MB BChir FRCPC FRCP(UK) AGAF FACG ${ }^{6}$
}

A series of credentialing guidelines for gastrointestinal endoscopic procedures performed in the management of adult patients has been developed by the Canadian Association of Gastroenterology (CAG) Endoscopy Committee. After review, the guidelines were approved by the Clinical Affairs Committee and endorsed by the Executive Board. In the present article, the CAG suggests specific guidelines for credentialing endoscopic retrograde cholangiopancreatography (ERCP). It is intended to be read in conjunction with the introductory article that outlines the principles of credentialing (1).

The CAG does not credential individuals for endoscopic procedures; that is the responsibility of the endoscopist's local institution or facility. The purpose of these guidelines is to provide a framework that will allow organizations to assess the training and competence of applicants to perform ERCP, as part of the credentialing process for the granting of privileges.

ERCP is an advanced endoscopic procedure

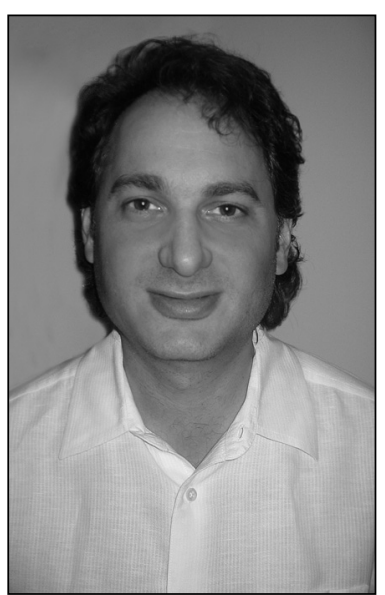

Dr Jonathon Springer

\section{COGNITIVE ASPECTS}

The cognitive aspects of ERCP are important and include an understanding of the indications for and contraindications to the procedure, the appropriateness of different diagnostic and therapeutic modalities in the management of obstructing and nonobstructing pancreaticobiliary ductal lesions (benign or malignant), informed consent, sedation, and reporting and documentation. The practitioner should be able to interpret the findings, implement an appropriate management plan and manage any complications that might arise during and after the procedure.

Understanding the risks and benefits of ERCP in certain patient groups, as well as alternative investigations (including their limitations and complications) such as computed tomography, magnetic resonance cholangiopancreatography (MRCP) and endoscopic ultrasound (EUS) is paramount for adequate management of patients with hepatobiliary and pancreatic disorders (2-4). For difficult cases, this usually involves a multidisciplinary creaticobiliary conditions. It is one of the most technically demanding and highest-risk procedures performed by endoscopists. Therefore, it requires comprehensive training and experience to perform competently.

The CAG credentialing criteria for ERCP apply to the investigation of adult patients, aged 18 years or older; the basic principles also apply to ERCP in pediatric patients but, because the number of procedures required to achieve and maintain competence may differ, guidance on credentialing for pediatric endoscopy is considered to be the responsibility of the North American Society for Pediatric Gastroenterology, Hepatology and Nutrition. approach, in which both surgical and radiological expertise can be obtained.

\section{Appropriate indications}

When first developed, ERCP was primarily a diagnostic technique. Subsequently, the development of noninvasive or less invasive techniques (computed tomography, MRCP, contrast ultrasound and EUS) for imaging the pancreaticobiliary system, with accuracy comparable with that of ERCP, has modified the indications for ERCP, such that it is now predominantly a therapeutic technique $(2,3)$.

\footnotetext{
${ }^{1}$ St Joseph's Health Centre, Toronto, Ontario; ${ }^{2}$ Division of Gastroenterology, University of British Columbia, Vancouver, British Columbia;

${ }^{3}$ Division of Gastroenterology and Hepatology, Departments of Medicine and Biostatistics, Bioinformatics and Epidemiology, Medical University

of South Carolina, Charleston, South Carolina, USA; ${ }^{4}$ Division of Gastroenterology, University of Western Ontario, London, Ontario;

${ }^{5}$ Division of Gastroenterology, McGill University, Montreal, Quebec; ${ }^{6}$ Division of Gastroenterology, McMaster University, Hamilton, Ontario Correspondence: Dr David Armstrong, Division of Gastroenterology, HSC-2F55, McMaster University Medical Centre, 1200 Main Street West,

Hamilton, Ontario L8N 325. Telephone 905-521-2100 ext 76404, fax 905-523-6048, e-mail armstro@mcmaster.ca

Received and accepted for publication May 5, 2008
} 


\begin{tabular}{l} 
TABLE 1 \\
Indications for endoscopic retrograde \\
cholangiopancreatography \\
\hline - Jaundice thought to be the result of biliary obstruction \\
- Clinical and biochemical or imaging data suggestive of pancreatic or biliary \\
tract disease \\
- Signs or symptoms suggesting pancreatic malignancy when direct imaging \\
results are equivocal or normal \\
- Pancreatitis of unknown etiology \\
- Preoperative evaluation of chronic pancreatitis or pancreatic pseudocyst \\
- Sphincter of Oddi manometry \\
- Endoscopic sphincterotomy \\
- Choledocholithiasis \\
- Papillary stenosis or sphincter of Oddi dysfunction, causing disability \\
- Facilitate biliary stent placement or balloon dilation \\
- Sump syndrome \\
- Choledochocele \\
- Ampullary carcinoma in poor surgical candidates \\
- Access to pancreatic duct \\
- Stent placement across benign or malignant strictures, fistulae, \\
postoperative bile leak or large common bile duct stones \\
- Balloon dilation of ductal strictures \\
- Nasobiliary drain placement \\
- Pseudocyst drainage in appropriate cases \\
- Tissue sampling from pancreatic or bile ducts \\
- Pancreatic therapeutics \\
\hline
\end{tabular}

Data from references 5 and 6

Knowledge of appropriate indications and contraindications is essential (5-7). ERCP is most commonly used for the management of cholangitis, bile duct stones, pancreatic and biliary strictures, leaks, tumours, pancreatic stones and pseudocysts, although, it remains applicable in other pancreaticobiliary conditions. The American Society for Gastrointestinal Endoscopy has defined a list of appropriate indications for ERCP (Table 1) $(5,6)$, and has recommended that an indication should be documented for each procedure and that there should be written justification if ERCP is performed for a nonstandard indication (6).

\section{Technical skills}

\section{TECHNICAL ASPECTS}

Minimum number of procedures: The number of procedures completed during training is, currently, the only objective measure available to assess competence and, subsequently, to evaluate maintenance of competence to perform ERCP. While other measures, such as cannulation rates and complication rates, are important, there are few objective mechanisms to assess these parameters. The most recent guidelines approved by the Society of American Gastrointestinal and Endoscopic Surgeons eschew specific numbers (7) but, in the absence of other metrics, most guidelines recommend that a minimum number of procedures should be completed as a basis for assessing a trainee's competence. The previous CAG guidelines, published in 1997 (8), recommended at least 180 procedures; however, the practice of ERCP has undergone extensive changes over the past decade. The American Society for Gastrointestinal Endoscopy recommends that at least 200 ERCPs, including 40 sphincterotomies and 10 stent placements, be performed before competence can be assessed (9). The Gastroenterological Society of Australia (10) also recommends at least 200 unassisted and complete ERCPs. However, this group recommends a minimum of 80 supervised, but independently performed, sphincterotomies, and the placement of a minimum of 60 stents and/or nasobiliary drains.

A study (11) of 17 gastroenterology fellows at various stages of training during 1796 consecutive ERCPs, found that fellows achieved overall competence after completing 180 to 200 ERCPs. However, subsequent studies $(12,13)$ have reported that success rates of over $80 \%$ for deep biliary cannulation might not be achieved until trainees have performed more than 300 to 400 procedures. An analysis (14) of outcomes, based on endoscopists' experience, found that learning endoscopic sphincterotomy techniques required a minimum of 40 procedures, but the complication rate decreased further after 100 procedures.

Performance of a specific, predefined number of procedures does not guarantee competence in ERCP, and a practitioner's technical competence should be assessed on an individual basis. Indeed, a recent review (15) has proposed that interested trainees who have proven endoscopic competence should be selected for specialist training in ERCP and EUS only after an assessment period during which 50 to 100 ERCPs are performed. Subsequent assessment should encompass not only the number of supervised procedures completed without assistance but also other standardized metrics $(16,17)$ including, for example, single-operator learning curves for deep biliary cannulation $(12,18)$.

\section{Success rates}

Cannulation rates: Cannulation of the duct of interest is the foundation for successful diagnostic and therapeutic ERCP. Successful cannulation may help to avoid the need for a second ERCP or percutaneous transhepatic cholangiography to complete the assessment.

Competent endoscopists should have successful cannulation rates of at least $80 \%$ to $85 \%(6,8)$. In clinical series, successful cannulation rates of $95 \%$ or higher have been consistently achieved by experienced endoscopists (19), and success rates of at least $80 \%$ are the goal of training programs in $\operatorname{ERCP}(20,21)$, although higher rates of $85 \%$ or $90 \%$ have been endorsed (22) or recommended $(15,23)$. It has been demonstrated that endoscopists who perform more than two sphincterotomies per week have higher cannulation rates of the biliary tree (24). A study (22) among surgery fellows found that those without previous endoscopic experience required 148 cases to reach an $85 \%$ success rate for cannulation. However, the implication that this is an appropriate threshold for surgery fellows or, indeed, for any ERCP trainee, has been challenged (25). Furthermore, the notion that the completion of 200 procedures constitutes a reasonable threshold for achieving competence may be unrealistic in light of a survey of ERCP practice in the United Kingdom, which reported a cannulation rate of only $66 \%$ among senior trainees who had completed more than 200 ERCPs (13).

Therapeutic interventions: The most common procedures performed during ERCP are stone extraction, relief of biliary obstruction and stent placement for bile leaks. These procedures should be achievable in at least $85 \%$ of cases (6). 
Bile duct clearance rates for all bile duct stones as high as 99\% have been reported in some expert endoscopy centres (26). It is expected that a competent ERCP endoscopist should achieve bile duct clearance in at least $85 \%$ of cases through the use of sphincterotomy and balloon or basket stone extraction, and in more than $90 \%$ of cases with the use of mechanical lithotripsy when necessary (6).

Indications for placement of a biliary stent to treat an obstruction below the bifurcation include pancreatic cancer, nonextractable or large common bile duct stones and benign strictures (chronic pancreatitis, after biliary surgery) (6). A competent ERCP endoscopist should be able to place a biliary stent for the relief of nonhilar biliary obstruction in more than $80 \%$ to $90 \%$ of patients (16).

\section{Complication rates}

ERCP is generally regarded as one of the most complicated of endoscopic procedures, with morbidity and mortality rates of $5 \%$ to $10 \%$ and $0.1 \%$ to $1 \%$, respectively $(5,24)$. Recently, some studies (27-29) have suggested that morbidity can be minimized by the appropriate use of ERCP performed by skilled advanced endoscopists, in appropriate patients, using adapted equipment. An analysis (14) of outcomes of sphincterotomy found that endoscopists with a case frequency of more than 40 procedures per year had a significantly lower complication rate than those with a lower case frequency. Another study (30) reported a lower complication rate among endoscopists who performed more than one sphincterotomy per week than among those who performed fewer than this.

The incidence of complications such as pancreatitis and postsphincterotomy bleeding, recorded by an individual endoscopist, should be comparable with those reported in the literature. Complication rates of up to $10 \%$ of patients have been demonstrated in multicentre trials (30). The major complications associated with ERCP are pancreatitis, postsphincterotomy hemorrhage, infectious complications (eg, cholangitis, cholecystitis and infection of pancreatic fluid collections) and perforation $(6,31)$.

The rate of ERCP-induced pancreatitis is generally reported to be approximately $1 \%$ to $7 \%(30-32)$. Patient selection and physician experience $(24,33)$ are critical aspects in minimizing complications and maximizing procedural success. Patient factors associated with a greater risk of pancreatitis include a history of post-ERCP pancreatitis, female sex, suspected sphincter of Oddi dysfunction and the absence of chronic pancreatitis $(24,33)$. There has been little evidence that case volume is a factor in determining postprocedural pancreatitis rates, but it has been proposed that few endoscopists perform sufficient numbers of procedures to demonstrate a further reduction in complication rates, compared with those who perform less than one case per week (29).

The expected rate of major postsphincterotomy bleeding is approximately $2 \%(6,30,32)$. Risk factors for postsphincterotomy bleeding include the presence of hemodialysis, bleeding at the time of the sphincterotomy, active cholangitis, abnormal coagulation status and low endoscopist case volume (less than one case per week) $(30,34)$. In addition, the risk of postprocedural bleeding is higher when an ampullectomy (35) or transmural pseudocyst drainage (36) is performed.

Cholangitis has been reported in $1 \%$ or fewer and cholecystitis in $0.2 \%$ to $0.5 \%$ of ERCP procedures $(6,31)$, while the overall incidence of perforation has been reported to be less than $1 \%$ in patients with normal anatomy $(6,32)$. The use of pancreatic stents to prevent pancreatitis and avoidance of precut sphincterotomy (ie, more skilled at selective cannulation) are two newer methods that might decrease risk, yet add complexity to the case $(27,29)$.

\section{TRAINING}

Successful performance of ERCP requires a detailed understanding and knowledge of the anatomy, pathology and physiology of the hepatobiliary and pancreatic systems, and their imaging. This knowledge is generally acquired in the context of a multidisciplinary hepatobiliary-pancreatic academic fellowship training program. ERCP requires significant focused training and experience to maximize success and safety $(11,37)$. A study $(22)$ among surgery fellows found that an average of seven months of training in ERCP was required to reach the desired success level ( $85 \%$ cannulation rate). However, success rates may be markedly lower than this in practice (13) and it has been proposed, on more than one occasion, that ERCP training be limited to a cadre of gastroenterology trainees $(15,38)$.

The acquisition of the technical skills necessary for ERCP by Canadian gastroenterology trainees generally occurs in the context of an advanced endoscopy training program, lasting one or two years after completion of the mandatory two-year subspecialty program. The time and resources needed to impart and acquire the necessary hand-eye coordination skills has led to the development of a variety of training simulators (39). Several teaching models are now available for ERCP, including live, anesthetized porcine models and, more recently, harvested porcine organ preparations and computer-based endoscopy simulators (39-42). A study (41) compared the performance of three ERCP training models (computer simulator, harvested porcine organ, live anesthetized pig) among 20 endoscopists. The harvested porcine organ model scored highest for realism, usefulness and performance, while the computer simulator scored lowest for realism. It has been suggested that models may accelerate training, but that computer simulators are only suitable for the initial steps of training $(39,40)$.

Changes in the indications for ERCP, the increased availability of alternative diagnostic modalities such as EUS and MRCP, and recognition of the need to document competence for graduates of training programs will have major implications for the future of ERCP training programs $(15,43-45)$. It is probable that decreasing numbers and increasing complexity of procedures performed in clinical practice, allied with the need for more prolonged, intensive, closely supervised training programs (10), will lead to a reduction in the number of training programs and an increase in the requirements for those participating, both as trainers and as trainees.

\section{MAINTENANCE OF COMPETENCE}

Unfortunately, attainment of competence does not guarantee a continued ability to perform an advanced procedure such as ERCP, both safely and effectively. Case volume is an independent predictor of ERCP-related complications $(30,46-48)$ and outcomes (24). Complications are more likely for endoscopists performing less than 40 to $50 \mathrm{ERCP}$ procedures annually and for centres performing less than 200 ERCP procedures annually. Again, as for training, an accurate assessment of competence would be better achieved by the use of a personal report card to document, for example, deep biliary cannulation and complication rates $(12,17,18,49)$. 


\section{SUMMARY}

Technical competence for ERCP can be assessed after 200 procedures; however, completion of a specified number of procedures does not imply competence, and target success rates may not be achieved until trainees have completed 350 to 400 procedures $(12,13)$. It is recommended that the documentation of competence should be based on the completion of at least 200 unassisted procedures, and that this should include at least 80 supervised, independently performed sphincterotomies and the placement of at least 60 biliary stents or nasobiliary drains (9-11). Competence in performing ERCP should include the documented ability to cannulate the targeted duct in at least $85 \%$ of cases and, when appropriate, to clear the bile duct (by sphincterotomy or balloon/basket stone extraction) or place a biliary drainage device in at least $85 \%$ of cases $(6,16,26)$.

Complication rates should be comparable with those reported in the literature; that is, an overall morbidity rate that is under $10 \%$ for all patients and an ERCP-related mortality rate that is less than $1 \%$ for all patients $(5,6,24,30-34)$. Data on success $(24)$ and complication $(14,30,33,34)$ rates suggest that to maintain their skills in ERCP, endoscopists should perform an average of one or more procedures per week.

Nontechnical components of competence (knowledge of expected pathology, judgment regarding biopsy and therapy, knowledge of alternative management options, indications for and contraindications to ERCP, informed consent, immediate postprocedural management) require a training program that generally involves a minimum of 12 months $(13,15,22)$. Although endoscopic simulators may shorten the early phase of technical training, it is not clear how the rapid acquisition of apparent competence using a simulator translates into actual ERCP performance in clinical practice.

Institutions that grant privileges for ERCP should be encouraged to develop endoscopic reporting mechanisms and databases so that endoscopists may explicitly monitor the quality of their practice and effect improvements if they identify deficiencies, thus maintaining procedural competence and optimizing clinical care over the long term (17). This is particularly important for ERCP, which is one of the most challenging endoscopic procedures, with the potential for significant morbidity and mortality.

ACKNOWLEDGEMENTS: This manuscript was produced with the invaluable assistance of Pauline Lavigne, and the members of the Endoscopy Committee and Clinical Affairs Committee of the Canadian Association of Gastroenterology. At the time of submission, David Armstrong was Chair of the Endoscopy Committee, Robert Enns was past Chair of the Endoscopy Committee and Alan Barkun was past Chair of the Clinical Affairs Committee for the Canadian Association of Gastroenterology.

\section{REFERENCES}

1. Armstrong D, Enns R, Ponich T, Romagnuolo J, Springer J, Barkun AN. Canadian credentialing guidelines for endoscopic privileges: An overview. Can J Gastroenterol 2007;21:797-801.

2. Romagnuolo J, Bardou M, Rahme E, Joseph L, Reinhold C, Barkun AN. Magnetic resonance cholangiopancreatography: A meta-analysis of test performance in suspected biliary disease. Ann Intern Med 2003;139:547-57.

3. Tse F, Barkun JS, Barkun AN. The elective evaluation of patients with suspected choledocholithiasis undergoing laparoscopic cholecystectomy. Gastrointest Endosc 2004;60:437-48.

4. Menon K, Barkun AN, Romagnuolo J, et al. Patient satisfaction after MRCP and ERCP. Am J Gastroenterol 2001;96:2646-50.

5. Johanson JF, Cooper G, Eisen GM, et al; American Society of Gastrointestinal Endoscopy Outcomes Research Committee. Quality assessment of ERCP. Endoscopic retrograde cholangiopacreatography. Gastrointest Endosc 2002;56:165-9.

6. Baron TH, Petersen BT, Mergener K, et al. Quality indicators for endoscopic retrograde cholangiopancreatography. Gastrointest Endosc 2006;63(4 Suppl):S29-34.

7. Society of American Gastrointestinal and Endoscopic Surgeons (SAGES) Guidelines Committee. Guidelines for training in diagnostic and therapeutic endoscopic retrograde cholangiopancreatography (ERCP). Surg Endosc 2007;21:1010-1.

8. Cockeram A. Canadian Association of Gastroenterology Practice Guideline for clinical competence in diagnostic and therapeutic endoscopic retrograde cholangiopancreatography. Can J Gastroenterol 1997;11:535-8.

9. Eisen GM, Baron TH, Dominitz JA, et al; American Society for Gastrointestinal Endoscopy. Methods of granting hospital privileges to perform gastrointestinal endoscopy. Gastrointest Endosc 2002;55:780-3.

10. Conjoint committee for the recognition of training in gastrointestinal endoscopy. Gastroenterological Society of Australia. Information for Registrants. <http://conjoint.gesa.org.au/ information.html > (Version current at May 5, 2008).

11. Jowell PS, Baillie J, Branch MS, Affronti J, Browning CL, Bute BP. Quantitative assessment of procedural competence. A prospective study of training in endoscopic retrograde cholangiopancreatography. Ann Intern Med 1996;125:983-9.

12. Verma D, Gostout CJ, Petersen BT, Levy MJ, Baron TH, Adler DG. Establishing a true assessment of endoscopic competence in

ERCP during training and beyond: A single-operator learning curve for deep biliary cannulation in patients with native papillary anatomy. Gastrointest Endosc 2007;65:394-400.

13. Williams EJ, Taylor S, Fairclough P, et al; BSG Audit of ERCP. Are we meeting the standards set for endoscopy? Results of a large-scale prospective study of endoscopic retrograde cholangiopancreatograph practice. Gut 2007;56:821-9.

14. Rabenstein T, Schneider HT, Nicklas M, et al. Impact of skill and experience of the endoscopist on the outcome of endoscopic sphincterotomy techniques. Gastrointest Endosc 1999;50:628-36.

15. Baillie J, Testoni PA. Are we meeting the standards set for ERCP? Gut 2007;56:744-6. (Erratum in 2007;56:1644).

16. Cotton PB. Income and outcome metrics for the objective evaluation of ERCP and alternative methods. Gastrointest Endosc 2002;56(6 Suppl):S283-90.

17. Cotton PB, Hawes RH, Barkun A, Ginsberg GG, Amman S, Cohen J, Ponsky J, Rex DK, Schembre D, Wilcox CM. Excellence in endoscopy: towards practical metrics. Gastrointest Endosc 2006;63:286-91.

18. Cass OW. Endoscopic ability and disability. Gastrointest Endosc 2007;65:401-2.

19. Schlup MM, Williams SM, Barbezat GO. ERCP: A review of technical competency and workload in a small unit. Gastrointest Endosc 1997;46:48-52.

20. Jowell PS. Endoscopic retrograde cholangiopancreatography: Toward a better understanding of competence. Endoscopy 1999:31:755-7.

21. Chutkan RK, Ahmad AS, Cohen J, et al; ERCP Core Curriculum prepared by the ASGE Training Committee. ERCP core curriculum. Gastrointest Endosc 2006;63:361-76

22. Vitale GC, Zavaleta CM, Vitale DS, Binford JC, Tran TC, Larson GM. Training surgeons in endoscopic retrograde cholangiopancreatography. Surg Endosc 2006;20:149-52.

23. Joint Advisory Group on Gastrointestinal Endoscopy. Guidelines for individuals in training. General Recommendations on Training in Gastrointestinal Endoscopy. < http://www.thejag.org.uk/ TrainingandAccreditation/tabid/67/Default.aspx > (Version current at May 22, 2008)

24. Freeman ML, DiSario JA, Nelson DB, et al. Risk factors for post-ERCP pancreatitis: A prospective, multicenter study. Gastrointest Endosc 2001;54:425-34. 
25. García-Cano J. 200 supervised procedures: The minimum threshold number for competency in performing endoscopic retrograde cholangiopancreatography. Surg Endosc 2007;21:1254-5.

26. Carr-Locke DL. Therapeutic role of ERCP in the management of suspected common bile duct stones. Gastrointest Endosc 2002;56(6 Suppl):S170-4.

27. Freeman ML. Adverse outcomes of ERCP. Gastrointest Endosc 2002;56(6 Suppl):S273-82.

28. Freeman ML. Post-ERCP pancreatitis: Patient and technique-related risk factors. JOP 2002;3:169-76.

29. Freeman ML. Adverse outcomes of endoscopic retrograde cholangiopancreatography: Avoidance and management. Gastrointest Endosc Clin N Am 2003;13:775-98, xi.

30. Freeman ML, Nelson DB, Sherman S, et al. Complications of endoscopic biliary sphincterotomy. N Engl J Med 1996;335:909-18.

31. Mallery JS, Baron TH, Dominitz JA, et al; Standards of Practice Committee. American Society for Gastrointestinal Endoscopy. Complications of ERCP. Gastrointest Endosc 2003;57:633-8.

32. Freeman ML, Guda NM. Prevention of post-ERCP pancreatitis: A comprehensive review. Gastrointest Endosc 2004;59:845-64.

33. Freeman ML. Complications of endoscopic biliary sphincterotomy: A review. Endoscopy 1997;29:288-97.

34. Nelson DB, Freeman ML. Major hemorrhage from endoscopic sphincterotomy: Risk factor analysis. J Clin Gastroenterol 1994;19:283-7.

35. Cheng CL, Sherman S, Fogel EL, et al. Endoscopic snare papillectomy for tumors of the duodenal papillae. Gastrointest Endosc 2004;60:757-64.

36. Baron TH, Harewood GC, Morgan DE, Yates MR. Outcome differences after endoscopic drainage of pancreatic necrosis, acute pancreatic pseudocysts, and chronic pancreatic pseudocysts. Gastrointest Endosc 2002;56:7-17.
37. Sivak MV Jr. "Trained in ERCP". Gastrointest Endosc 2003;58:412-4.

38. Baillie J. ERCP training: For the few, not for all. Gut 1999;45:9-10.

39. Baillie J. Endoscopic retrograde cholangiopancreatography simulation. Gastrointest Endosc Clin N Am 2006;16:529-42, viii.

40. Bar-Meir S. Simbionix simulator. Gastrointest Endosc Clin N Am 2006;16:471-8, vii.

41. Sedlack R, Petersen B, Binmoeller K, Kolars J. A direct comparison of ERCP teaching models. Gastrointest Endosc 2003;57:886-90.

42. Matthes K, Cohen J. The Neo-Papilla: A new modification of porcine ex vivo simulators for ERCP training (with videos). Gastrointest Endosc 2006;64:570-6.

43. Jenkins JT, Glass G, Ballantyne S, Fullarton GM. Effect of MRCP introduction on ERCP practice: Are there implications for service and training? Gut 2006;55:1365-6.

44. Sahel J, Barthet M, Gasmi M. The substitution of endoscopic ultrasonography for endoscopic retrograde cholangiopancreatography: Implications for service development and training. Eur J Gastroenterol Hepatol 2004;16:291-4.

45. Meenan J, Tibble J, Prasad P, Wilkinson M. The substitution of endoscopic ultrasound for endoscopic retrograde cholangiopancreatography: Implications for service development and training. Eur J Gastroenterol Hepatol 2004;16:299-303.

46. Freeman ML, DiSario JA, Nelson DB, et al. Risk factors for post-ERCP pancreatitis: A prospective, multicenter study. Gastrointest Endosc 2001;54:425-34.

47. Loperfido S, Angelini G, Benedetti G, et al. Major early complications from diagnostic and therapeutic ERCP: A prospective multicenter study. Gastrointest Endosc 1998;48:1-10.

48. Freeman ML. Procedure-specific outcomes assessment for endoscopic retrograde cholangiopancreatography. Gastrointest Endosc Clin N Am 1999;9:639-47, vii.

49. Cotton PB. How many times have you done this procedure, doctor? Am J Gastroenterol 2002;97:522-3. 


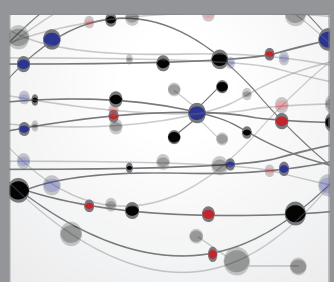

The Scientific World Journal
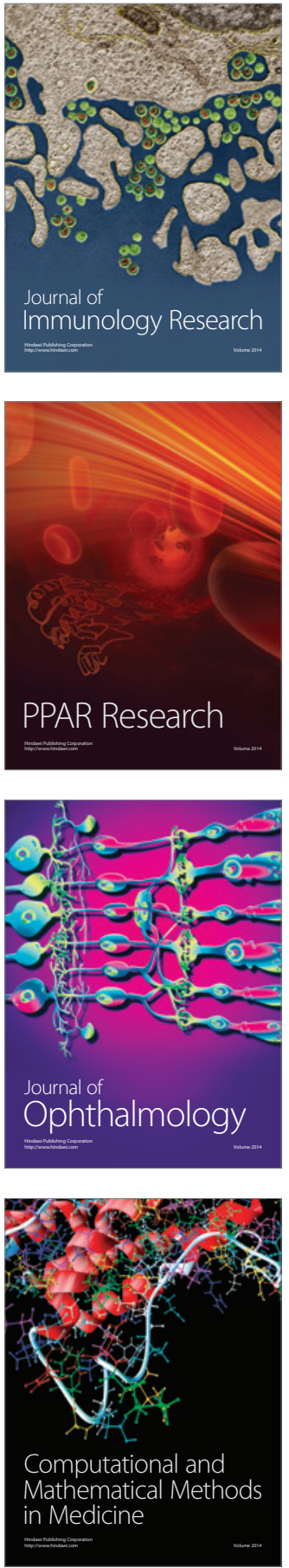

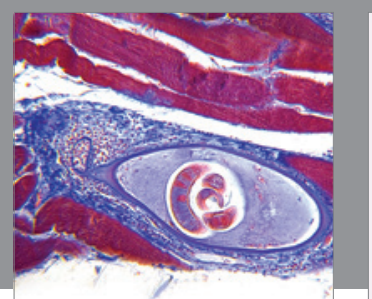

Gastroenterology Research and Practice

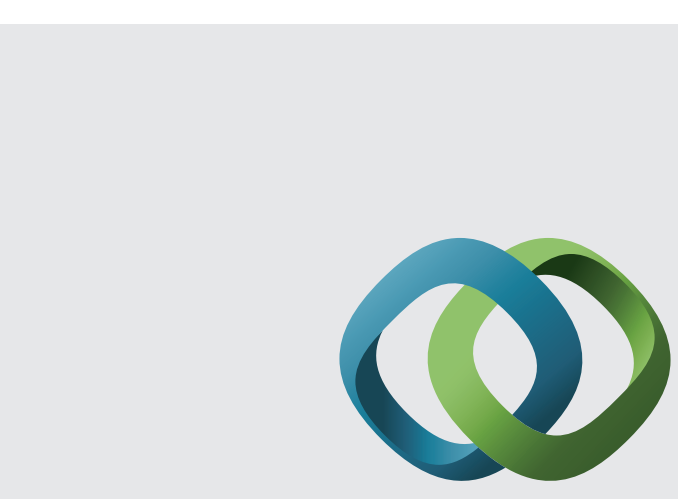

\section{Hindawi}

Submit your manuscripts at

http://www.hindawi.com
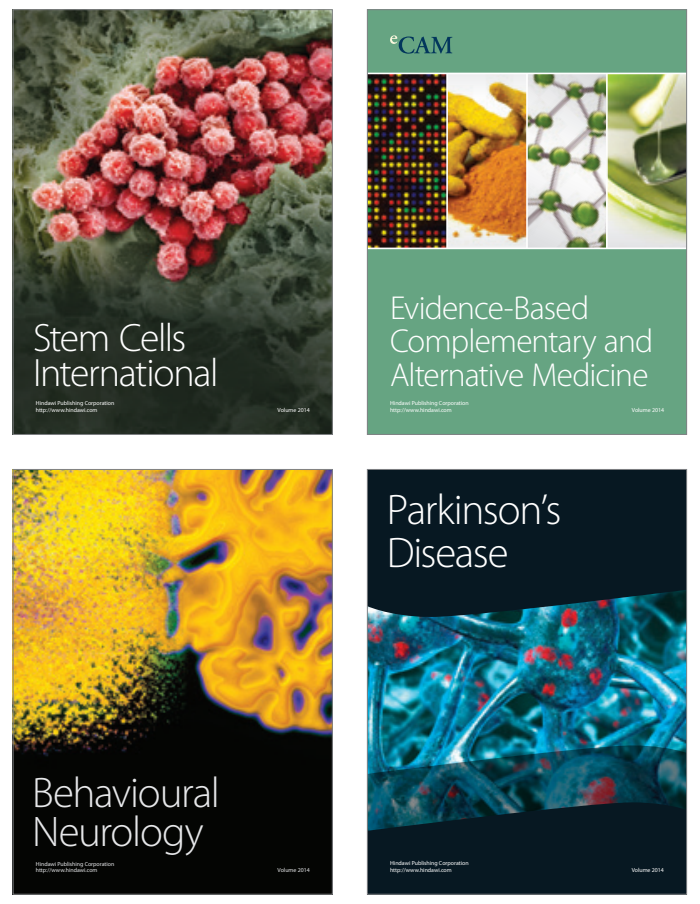
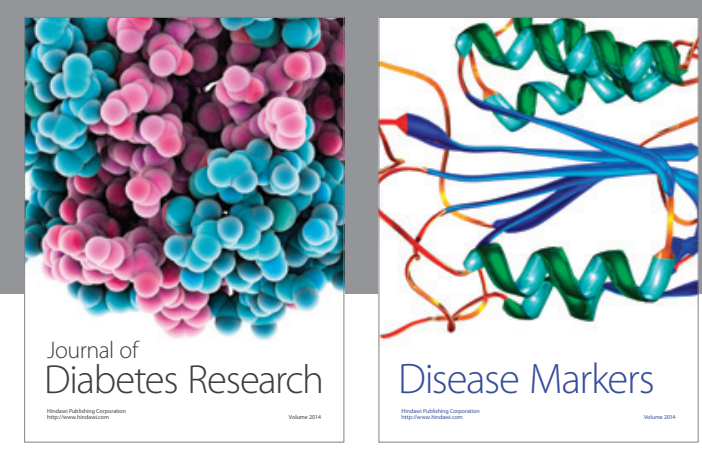

Disease Markers
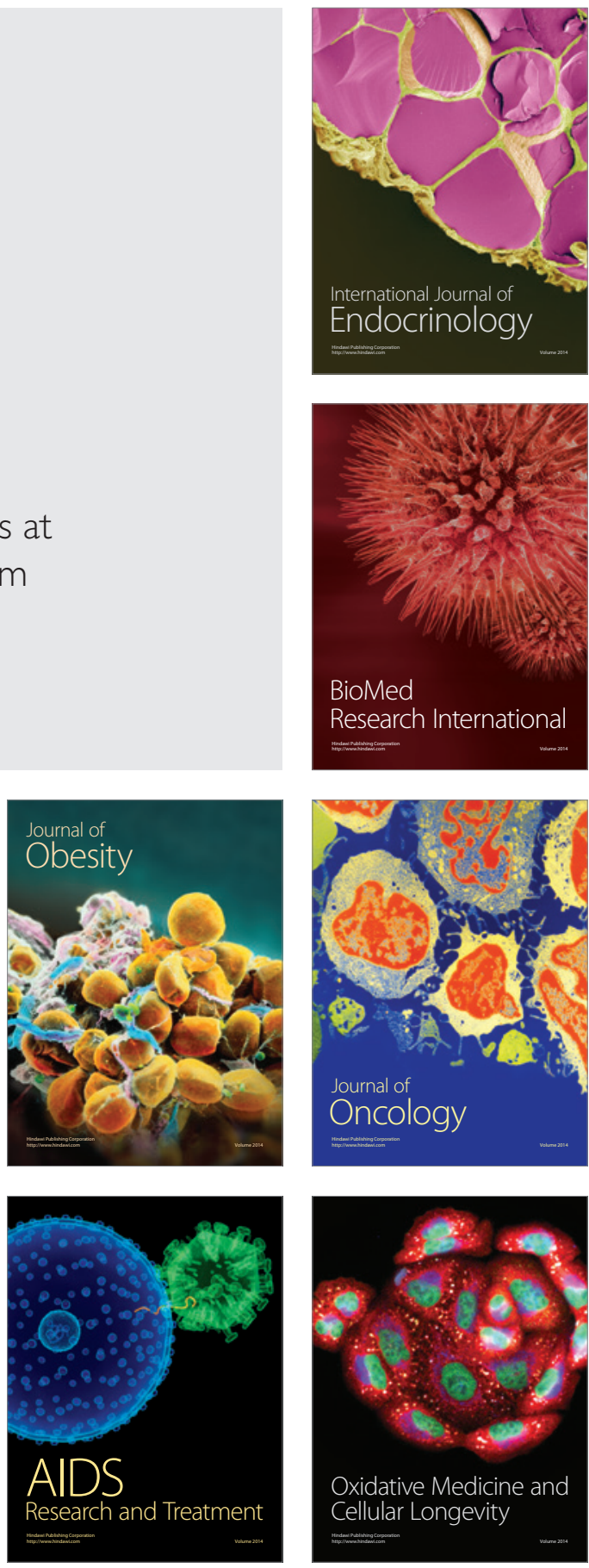